Mycobacterium tuberculosis by identifying mutations in the 16S rRNA gene. J Clin Microbiol. 1998;36:1220-5.

7. Monot M, Honoré N, Garnier T, Zidane N, Sherafi D, Paniz-Mondolfi A, et al. Comparative genomic and phylogeographic analysis of Mycobacterium leprae. Nat Genet. 2009;41:1282-9. https://doi.org/10.1038/ng.477

8. Weng X, Xing Y, Liu J, Wang Y, Ning Y, Li M, et al. Molecular, ethno-spatial epidemiology of leprosy in China: novel insights for tracing leprosy in endemic and non endemic provinces. Infect Genet Evol. 2013;14:361-8. https:/ / doi.org/10.1016/j.meegid.2012.12.009

9. Benjak A, Avanzi C, Singh P, Loiseau C, Girma S, Busso P, et al. Phylogenomics and antimicrobial resistance of the leprosy bacillus Mycobacterium leprae. Nat Commun. 2018; 9:352. https:/ / doi.org/10.1038/s41467-017-02576-z

Address for correspondence: Arnab Pain, King Abdullah University of Science and Technology, BESE Division, ThuwalJeddah, 239556900, Saudi Arabia; email: arnab.pain@kaust.edu.sa

\section{Three New Cases of Melioidosis, Guadeloupe, French West Indies}

\author{
Bénédicte Melot, Sylvaine Bastian, Nathalie Dournon, \\ Eric Valade, Olivier Gorgé, Anne Le Fleche, \\ Charlotte Idier, Mireille Vernier, Elisabeth Fernandes, \\ Bruno Hoen, Sébastien Breurec, Michel Carles \\ Author affiliations: University Hospital of Guadeloupe, \\ Pointe-à-Pitre, France (B. Melot, S. Bastian, N. Dournon, C. Idier, \\ B. Hoen, S. Breurec, M. Carles); Ecole du Val-de-Grâce, Paris, \\ France (E. Valade); Aix Marseille University, Marseille, France \\ (E. Valade, O. Gorgé); Institut Pasteur, Paris (A. Le Fleche); \\ Hospital of Basse-Terre, Basse-Terre, France (M. Vernier, \\ E. Fernandes); Pasteur Institute of Guadeloupe, Pointe-à-Pitre \\ (S. Breurec); University of the French West Indies and French \\ Guiana, Pointe-à-Pitre (B. Hoen, S. Breurec, M. Carles)
}

DOI: https://doi.org/10.3201/eid2603.190718

Melioidosis has been detected in the Caribbean, and an increasing number of cases has been reported in the past few decades, but only 2 cases were reported in Guadeloupe during the past 20 years. We describe 3 more cases that occurred during 2016-2017 and examine arguments for increasing endemicity.
M elioidosis, caused by the telluric gram-negative rod Burkholderia pseudomallei, is endemic in Southeast Asia and northern Australia (1) but may be underdiagnosed in other tropical regions (2). Increasing occurrences have been reported in the Caribbean during the past few decades among persons with no exposure to known endemic areas (3-5). Tropical environmental conditions and the presence of this bacterium in soil samples in the Caribbean support the plausibility of endemicity (3). We describe 3 new cases detected in Guadeloupe during 2016-2017.

Patient 1 was a 54 -year-old man, receiving renal replacement therapy, with a history of hypertensive vascular nephropathy. He developed a pulmonary form of melioidosis in November 2016. Thoracoabdominal computed tomography (CT) scan showed bilateral nodular lesions. B. pseudomallei grew from bronchoalveolar lavage fluid obtained by fiberoptic bronchoscopy. Treatment with ceftazidime $(6 \mathrm{~g} / \mathrm{d}$ intravenously) was given for 2 weeks and switched to trimethoprim/sulfamethoxazole (TMP/SMX) (320/1,600 mg $2 \times / d$ orally) for 1 month, then changed to doxycycline because rash developed. The patient complied poorly with treatment; he died in March 2017 under unknown circumstances.

Patient 2 was a 66-year-old woman with a history of arterial hypertension and diabetes mellitus, a subcutaneous abscess in the prepubic area surgically treated without microbiological identification (June 2016), a lumbar hematoma (March 2017), and bacteremic obstructive pyelonephritis caused by Escherichia coli (April 2017). In April 2017, she developed a severe and disseminated form of melioidosis with pneumonia, bacteremia, and deep abscess. CT scan showed multiple pulmonary nodes consistent with hematogenous pneumonia, a deep abscess between kidney and psoas, and splenic emboli. B. pseudomallei was isolated from blood cultures performed at admission and from the abscess. The patient developed multiple complications: acute respiratory distress syndrome, systemic candidiasis, renal failure, hemodynamic failure, nonspecific encephalopathy, refractory septic shock related to catheter infection, and bacteremia caused by extended spectrum $\beta$-lactamase Klebsiella pneumoniae. In the intensive care unit, she was treated with ceftazidime $(6 \mathrm{~g} / \mathrm{d}$ for $24 \mathrm{~d})$, then with meropenem $(1 \mathrm{~g} 3 \times / \mathrm{d})$ plus TMP/SMX (320/1,600 mg $2 \times / \mathrm{d})$. Blood cultures grew B. pseudomallei until day 40 . The patient died on day 60 from multiple organ failure.

Patient 3 was a 52-year-old man with a history of chronic alcoholism. He developed pneumonia in April 2017. Thoracic tomography showed an excavated condensation of the right middle lobe, right 
lower infiltrates, and multiple right hilar nodes. Bronchoalveolar lavage fluid contained B. pseudomallei. Intravenous ceftazidime $(2 \mathrm{~g} 3 \times / \mathrm{d})$ for 40 days followed by oral TMP/SMX (320/1,600 mg $2 \times / \mathrm{d})$ slowly improved the clinical status, but 1 month after starting oral antimicrobial drug therapy, he had a drug reaction that caused eosinophilia and systematic symptoms. He died a year later despite appropriate treatment.

All patients were born and had always lived in the western part of Guadeloupe and Les Saintes islands, the rainiest places in Guadeloupe (1,500-5,500 $\mathrm{mm}$ of rainfall per year in 2017 [Météo France, http:/ / www.meteofrance.gp/climat/pluies-annuelles/ rr_an_guadeloupe]). The patients reported no travel history to endemic countries. All had a history of potential occupational or recreational exposure to $B$. pseudomallei (as farmers, gardeners) and predisposing risk factors, such as diabetes mellitus, chronic renal diseases, and alcoholism (1). The clinical manifestations of disease were classical, but all patients experienced severe side effects during their treatments, and the mortality rate was $100 \%$ (Table), which is much higher than in most series of reported cases, underlining the severity of this disease.

These 3 cases of melioidosis were identified over a 6-month period, in contrast with only 2 cases diagnosed and reported during the previous 20 years in Guadeloupe. The identification of the isolate from the first case was performed locally by the API-20NE system (bioMérieux, https://www.biomerieux.com) and confirmed by matrix-assisted laser desorption/ ionization time-of-flight (MALDI-TOF) mass spectrometry and by real-time PCR (6) at a reference laboratory in France. The isolates from the other cases were not identified correctly by the API-20NE system, as often described (7). However, after the first case, we were aware that a wrinkled colony-forming, oxidase-positive, gram-negative bacillus resistant to colistin and aminoglycosides could be B. pseudomallei. Thus, the strains were sent to the reference laboratory for confirmation. All the isolates were genotyped by multilocus sequence typing (8). They belonged to sequence type (ST) $92(n=2)$ and $95(n=1), 2$ clones previously described in Central and South America and Caribbean islands: Brazil (ST92), Puerto Rico (ST95), Martinique, and Mexico (ST92 and ST95 in both areas) (9). This finding highlights the potential role of this region as a reservoir for these clones.

Our experience suggests that the incidence of $B$. pseudomallei infection is probably underestimated in the Caribbean because of inadequate diagnostic laboratory facilities and the lack of knowledge about melioidosis among physicians and microbiologists. The tropical climate in this region provides suitable conditions for bacterial survival, and elevated alcoholism and diabetes rates among Caribbean populations cause weakened immunity that could lead to increased infection risk (10). Therefore, investigation of soil samples should be undertaken to identify the most likely sources of human infection in this area.

\begin{tabular}{|c|c|c|c|}
\hline Characteristic & Patient 1 & Patient 2 & Patient 3 \\
\hline Age, y & 54 & 66 & 52 \\
\hline Sex & $\mathrm{M}$ & $\mathrm{F}$ & $\mathrm{M}$ \\
\hline Place of birth & Guadeloupe & Guadeloupe & Guadeloupe \\
\hline Place of residence & Bouillante & Deshaies & Les Saintes \\
\hline Rainfall, $\mathrm{mm} / \mathrm{y}$ & $2,500-3,000$ & $1,500-2,000$ & $1,500-2,000$ \\
\hline Concurrent conditions & $\begin{array}{l}\text { Chronic renal failure (vascular } \\
\text { nephropathy) }\end{array}$ & Diabetes & Chronic alcohol intake \\
\hline Possible means of inoculation & Gardening without gloves & $\begin{array}{l}\text { Animals breeding, gardening } \\
\text { without gloves }\end{array}$ & $\begin{array}{l}\text { Animals breeding, gardening } \\
\text { without shoes }\end{array}$ \\
\hline $\begin{array}{l}\text { Clinical presentation according to } \\
\text { the Infectious Disease Association } \\
\text { of Thailand } \dagger\end{array}$ & $\begin{array}{c}\text { 1: Multifocal infection with } \\
\text { bacteremia ( } 45 \% \text { of cases, } 87 \% \\
\text { mortality) }\end{array}$ & $\begin{array}{c}\text { 3: Localized infection ( } 42 \% \text { of } \\
\text { cases, } 9 \% \text { mortality) }\end{array}$ & $\begin{array}{c}\text { 3: Localized infection ( } 42 \% \text { of } \\
\text { cases, } 9 \% \text { mortality) }\end{array}$ \\
\hline $\begin{array}{l}\text { Time from first clinical signs to } \\
\text { death }\end{array}$ & $11 \mathrm{mo}$ & $2 \mathrm{mo}$ & $16 \mathrm{mo}$ \\
\hline Organ involvement & Pneumonia & $\begin{array}{l}\text { Disseminated (psoas abscess, } \\
\text { lung abscesses, bacteremia) }\end{array}$ & Pneumonia \\
\hline MLST & ST92 & ST95 & ST92 \\
\hline Treatment & $\begin{array}{c}\text { Ceftazidime + TMP/SMX, then } \\
\text { doxycycline; TMP/SMX } \\
\text { discontinued due to rash }\end{array}$ & $\begin{array}{l}\text { Ceftazidime, meropenem, } \\
\text { TMP/SMX }\end{array}$ & $\begin{array}{l}\text { Ceftazidime + TMP/SMX; } \\
\text { TMP/SMX discontinued due } \\
\text { to DRESS syndrome }\end{array}$ \\
\hline Outcome & Death & Death & Death \\
\hline
\end{tabular}




\section{Acknowledgments}

We acknowledge the Departments of Infectious Diseases and Tropical Medicine, Intensive Care Medicine, and Microbiology of Pointe-à-Pitre University Hospital; L'Institut de Recherche Biomédicale des Armées, Brétigny-sur-Orge, France; and Cellule d'Intervention Biologique d'Urgence, Paris, France, for their valuable collaboration in the medical care, investigation, and participation for each case report.

\section{About the Author}

Dr. Melot is a medical doctor in infectious and tropical diseases at University Hospital of Guadeloupe, Pointe-àPitre, France, and holds a master's degree in public health and epidemiology. Her primary research interests include the study of tropical endemic infections.

\section{References}

1. Currie BJ, Ward L, Cheng AC. The epidemiology and clinical spectrum of melioidosis: 540 cases from the 20 year Darwin prospective study. PLoS Negl Trop Dis. 2010;4:e900. https:/ / doi.org/10.1371/journal.pntd.0000900

2. Limmathurotsakul D, Golding N, Dance DAB, Messina JP, Pigott DM, Moyes CL, et al. Predicted global distribution of Burkholderia pseudomallei and burden of melioidosis. Nat Microbiol. 2016;1:15008. https://doi.org/10.1038/ nmicrobiol.2015.8

3. Torres AG, Montufar FE, Gee JE, Hoffmaster AR, Elrod MG, Duarte-Valderrama C, et al. Melioidosis is in the Americas: a call to action for diagnosing and treating the disease. Am J Trop Med Hyg. 2018;99:563-4. https://doi.org/10.4269/ ajtmh.18-0418

4. Sanchez-Villamil JI, Torres AG. Melioidosis in Mexico, Central America, and the Caribbean. Trop Med Infect Dis. 2018;3:24. https://doi.org/10.3390/tropicalmed3010024

5. Benoit TJ, Blaney DD, Doker TJ, Gee JE, Elrod MG, Rolim DB, et al. A review of melioidosis cases in the Americas. Am J Trop Med Hyg. 2015;93:1134-9. https:/ / doi.org/10.4269/ajtmh.15-0405

6. Thibault FM, Valade E, Vidal DR. Identification and discrimination of Burkholderia pseudomallei, B. mallei, and $B$. thailandensis by real-time PCR targeting type III secretion system genes. J Clin Microbiol. 2004;42:5871-4. https:/ / doi.org/10.1128/JCM.42.12.5871-5874.2004

7. Glass MB, Popovic T. Preliminary evaluation of the API 20NE and RapID NF plus systems for rapid identification of Burkholderia pseudomallei and B. mallei. J Clin Microbiol. 2005;43:479-83. https://doi.org/10.1128/JCM.43.1.479483.2005

8. Godoy D, Randle G, Simpson AJ, Aanensen DM, Pitt TL, Kinoshita R, et al. Multilocus sequence typing and evolutionary relationships among the causative agents of melioidosis and glanders, Burkholderia pseudomallei and Burkholderia mallei. J Clin Microbiol. 2003;41:2068-79. https://doi.org/10.1128/JCM.41.5.2068-2079.2003

9. Hall CM, Jaramillo S, Jimenez R, Stone NE, Centner H, Busch JD, et al. Burkholderia pseudomallei, the causative agent of melioidosis, is rare but ecologically established and widely dispersed in the environment in Puerto Rico. PLoS Negl Trop Dis. 2019;13:e0007727. https:// doi.org/10.1371/ journal.pntd.0007727
10. Carrère $\mathrm{P}$, Fagour $\mathrm{C}$, Sportouch $\mathrm{D}$, Gane-Troplent $\mathrm{F}$, Hélène-Pelage J, Lang $\mathrm{T}$, et al. Diabetes mellitus and obesity in the French Caribbean: a special vulnerability for women? Women Health. 2018;58:145-59. https:/ / doi.org/10.1080/ 03630242.2017 .1282396

Address for correspondence: Bénédicte Melot, Delocalized Centers for Prevention and Care, Hospital of Cayenne, Av des Flamboyants, Cayenne 97306, French Guiana; email: melotb@gmail.com

\section{Coccidioidomycosis Skin Testing in a Commercially Insured Population, United States, 2014-2017}

\author{
Kaitlin Benedict, Orion Z. McCotter, \\ Brendan R. Jackson
}

Author affiliation: Centers for Disease Control and Prevention, Atlanta, Georgia, USA

DOI: https://doi.org/10.3201/eid2603.190798

Coccidioidomycosis skin testing appears to be uncommon, based on US health insurance claims data. Patient demographic features were consistent with the approval of the test for adults, but few patients had previous coccidioidomycosis diagnosis codes supporting its use for detecting delayed-type hypersensitivity in those with a history of pulmonary coccidioidomycosis.

occidioidal skin testing has been a valuable epi-
demiologic and clinical tool for estimating the
prevalence of previous Coccidioides spp. exposure and
monitoring treatment response (1-3). Such testing
could also be useful for evaluating healthy persons'
risk of developing coccidioidomycosis (3). The skin
test became commercially available again in 2014 af-
ter more than a decade; it is approved for adults $18-64$
of age who have a history of pulmonary coccidioido-
mycosis $(3,4)$. However, little is known about its use

${ }^{1}$ This work was presented in part at the 63rd Annual

Coccidioidomycosis Study Group Conference, Sacramento,

California, USA, April 5-6, 2019. 